\title{
FAECAL FAT VALUES ON PRESENT BRITISH DIETS BY
}

\author{
R. J. BROMFIELD \\ From the London School of Hygiene and Tropical Medicine
}

(RECEIVED FOR PUBLICATION, JUNE 2, 1949)

During a series of faecal fat analyses on samples of dried faeces (Soxhlet method) it was noted that the "normal" total fat content was usually within the range of $10 \%$ to $15 \%$, of which some $50 \%$ was split fatty acid. These values are significantly lower than those encountered in similar hospital patients before 1940 , and can readily be explained by the reduced fat content of the present diet. They do, however, lead to a consideration of the effects of the present low fat intake on conditions usually associated with fatty stools.

It is appreciated that an analysis of pooled three-day samples of faeces is desirable, but such collections are unpleasant, difficult to handle, and, in the majority of cases, not practicable. Hence the usual hospital practice of utilizing a single morning specimen has been followed. It is important, however, that any comparison of normal and pathological findings be made on patients receiving similar diets, particularly with regard to the intake of fat.

Fairley (1936) showed that in 56 out of 70 cases of tropical sprue the total faecal fat exceeded $25 \%$ of the dried faeces, with an overall average of $39.1 \%$ of total fat, of which $64.8 \%$ was split.

It will be seen that in the present series of 10 cases of tropical sprue the average total faecal fat was $34.2 \%$ of which $70.6 \%$ was split fatty acid, and in three cases of idiopathic steatorrhoea similar figures were obtained.

Normally, not more than $25 \%$ of the dried faeces should be fat, of which not more than $25 \%$ should be unsplit. When the total fat intake is low, split fat is almost completely absorbed, and even in health unsplit fat may form a higher proportion of the faecal fat, since some of it corresponds more or less to "starvation" faecal fat which may be regarded as fatty material excreted into the bowel or formed by degeneration of cell tissue, and not as a food residue (Harrison, 1947).

In the present somewhat limited series the average normal fat content of the dried faeces was $13.1 \%$, with a range of from $7.5 \%$ to $17.7 \%$ Splitting was somewhat low, the average split fat being only $54.3 \%$.

\section{Summary}

Although the normal total faecal fat and fatty acids in the stool have been somewhat diminished by restrictions in diet, the rule that normally not more than $25 \%$ of the dried faeces should be fat is still a sound generalization.

\section{REFERENCES}

Fairley, N. Hamilton (1936). Trans. R. Soc. trop. Med. Hyg., 30, 15. Harrison, G. A. (1947). Chemical Methods in Clinical Medicine. 3rd ed., p. 489. J. and A. Churchill.

TABLE

Fat Content of Dried Stool

\begin{tabular}{ll|c|c|c|c|c|c|c}
\hline \multirow{2}{*}{ Condition } & \multirow{2}{*}{$\begin{array}{c}\text { No. } \\
\text { of } \\
\text { Cases }\end{array}$} & \multicolumn{3}{|c|}{ Total Fat (\%) } & \multicolumn{3}{c}{ Split Fat (\%) } \\
\cline { 3 - 8 } & Minimum & Maximum & Mean & Minimum & Maximum & Mean \\
\hline $\begin{array}{l}\text { Normal } \\
\text { Tropical sprue }\end{array}$ & $\ldots$ & 20 & 7.5 & 17.7 & 13.1 & 29.1 & 86.4 & 54.3 \\
Idiopathic steatorrhoea & 10 & 24.2 & 45.7 & 34.2 & 61.8 & 82.0 & 70.6 \\
\end{tabular}

